\title{
Mecanismos de muerte neuronal en la isquemia cerebral
}

\author{
I. Ferrer
}

\author{
NEURONAL DEATH MECHANISMS IN CEREBRAL ISCHEMIA
}

\begin{abstract}
Summary. Introduction. Morphological and biochemical studies have shown an apoptotic component in neurons following either focal or global ischemia in adults, or hypoxia-ischemia during development. Development. Different factors, including transcription factors, members of the Bcl-2 family, caspases and trophic factors, participate in the cascade of events leading to cell death. Transcription factor c-Jun is induced and expressed in the three models of ischemia as a non-specific response to the ischemic stress. The role played by the different members of the Bcl-2 family is not clear in cerebral ischemia. It is feasible that Bcl-2 expression is not sufficient to protect nerve cells from dying in those animals with physiological dotations of this protein. Yet Bcl-xS may have a role in ischemia-induced cell death following global ischemia in the adult or hypoxia-ischemia during development. Recent studies have also shown a similar putative role of caspase 1 and caspase 3 following cerebral ischemia. Finally, the ischemic insult is usually accompanied by modifications in the expression of neurotrophins and receptors. Conclusions. Brain-derived neurotrophic factor (BDNF) administration preserves nerve cells from dying following focal or global ischemia in adults, and hypoxia-ischemia during development. This positive effect is probably dependent on the cross-signaling between BDNF and its specific receptor TrkB. Cumulative evidence in experimental models indicates BDNF as a putative agent in the treatment of cerebral ischemia in humans [REV NEUROL 1999; 29: 515-21].
\end{abstract}

Key words. Apoptosis. Bax. Bcl-2. Bcl-x. Brain-derived neurotrophic factor. Caspase. C-jun N-terminal kinase-1. C-jun. Necrosis. TrkB.

\section{INTRODUCCIÓN}

El intento de comprender los mecanismos que controlan la supervivencia y muerte de las células ha llevado a diferentes clasificaciones basadas en aproximaciones morfológicas, bioquímicas y genéticas. Con el término de apoptosis se distingue una forma de muerte celular caracterizada morfológicamente por la condensación temprana y extrema de la cromatina y la formación de cuerpos apoptóticos, y bioquímicamente por la actuación temprana de endonucleasas que produce una fragmentación internucleosomal del ADN y que se manifiesta con un patrón en bandas múltiples de 180-200 pares de bases en la electroforesis sobre gel de agarosa de ADN aislado. La necrosis se caracteriza morfológicamente por la alteración temprana de las membranas celulares y de las organelas citoplásmicas, y bioquímicamente por la actuación al azar de proteasas y endonucleasas que dividen el ADN en múltiples fragmentos irregulares, hecho que se manifiesta como un patrón en mancha en la electroforesis sobre gel de agarosa del ADN aislado [1-3]. Una metodología reciente para observar individualmente células apoptóticas ha sido el marcaje in situ del ADN fragmentado, que se basa en la incorporación de nucleótidos dUTP a los terminales 3'-OH del ADN fragmentado, mediante la acción del enzima terminal deoxinucleotidil transferasa (TdT) [4]. La apoptosis se interpreta como unfenómeno activo que precisa de la síntesis de proteínas encar-

Recibido: 21.05.99. Aceptado: 25.05.99.

Unidad de Neuropatología. Servicio de Anatomía Patológica. Hospital Príncipes de España (Bellvitge). Departamento de Biología Celulary Anatomía Patológica. Universidad de Barcelona. Hospitalet de Llobregat, Barcelona, España.

Correspondencia: Prof. Isidro Ferrer. Unidadde Neuropatología. Servicio de Anatomía Patológica. Hospital Príncipes de España (Bellvitge). Feixa Llarga, s/n.E-08907 Barcelona.Fax: +34932045065.E-mail:iferrer@sakma.es

Estetrabajofuepresentadobajolosauspiciosdel GrupodeEstudiodeEnfermedades Cerebrovasculares, en el Simposio 'Neurotoxicidad, neuroprotección y ventana terapéutica en la isquemia cerebral' celebrado el 21 de mayo de 1999 durante el XI Congreso Nacional de la Sociedad Española de Neurología, Santiago de Compostela, 19 al 22 de mayo de 1999.

C 1999, REVISTA DENEUROLOGÍA gadas de llevar a término la muerte celular. Por este motivo, la apoptosis se considera una forma de muerte programada. La muerte natural durante el desarrollo normal es el paradigma de muerte programada, ya que afecta de un modo regular a todos los individuos y tiene funciones en la organogénesis y en el modelamiento fisiológico de los organismos pluricelulares durante el desarrollo. Sin embargo, no todas las muertes programadas durante el desarrollo normal tienen características morfológicas y bioquímicas de apoptosis [5].

El estudiogenético detallado de Caenorhabditis elegansha permitido descubrir la maquinaria que controla la muerte celular durante el desarrollo normal de este nematodo. Un aspecto interesante es la posterior comprobación que los productos de los denominados genes ced- 3 y ced- 9 , promotor y bloqueador de la muerte celular, respectivamente, en C. elegans, tienenhomólogos ampliados en los animales más evolucionados y particularmente en los mamíferos [6]. Así, ced-9 es homólogo de bcl-2, miembro a su vez de una amplia familia de genes que codifica diferentes proteínas, mientras que ced-3 es homólogo de ICE, un miembro de la familia de las caspasas [7-10].

A pesar del posible papel relevante de las familias bcl-2 y caspasas, el control de supervivencia y muerte celular es, en cualquier caso, mucho más complejo, e intervienen una lista creciente de distintos factores en las diferentes cascadas que pueden llevar a la muerte de una célula. Entre ellos, hay factores de transcripción producidos en la propia célula y sistemas sociales de supervivencia que dependen de poblaciones celulares vecinas [11-13].

Laconsecuenciaprevisibledeestos datoshasidoelestudiode la posible implicación de estos factores en los mecanismos de muerte y supervivencia celular en distintas condiciones naturales (fisiológicas) y patológicas, ya sea en modelos de muerte por apoptosis o en modelos de muerte por necrosis.

En este trabajo se revisan los datos experimentales paraconsiderar la muerte neuronal por apoptosis o por necrosis, así como los papeles del factor de transcripción c-jun y de c-jun $\mathrm{N}$-terminal cinasa-1 (JNK-1), de los miembros de la familia bcl-2, de las caspasas y del factor neurotrófico derivado del cerebro (BDNF, 
del inglés Brain-DerivedNeurotrophicFactor)en modelos experimentales de isquemia focal y de isquemia global en el adulto, y dehipoxia-isquemia en el animal en desarrollo.

\section{MUERTE NEURONAL EN LA ISQUEMIA CEREBRAL}

Clásicamente se ha consideradoque la muerte celular producida por isquemia es necrosis. Sin embargo, estudios recientes basados principalmente en el marcaje in situ del ADN fragmentado, combinado con la observación de un patrón en bandas en la electroforesis sobre gel de agarosa de ADN aislado, han sugerido rasgos apoptóticosenlamuerteneuronal secundariaaisquemiacerebral focal [14-16]. Estudios posteriores han mostrado que las células apoptóticas predominan en la región interna de los bordes del infarto (zona de penumbra) y que su presencia puede prolongarse durante varios días después delepisodioisquémico, loque sugiere la existencia de un reclutamiento temporal de células muertas por apoptosis durante el desarrollo del infarto $[17,18]$.

Por lo respecta a la isquemia global, también se ha demostrado la presencia de tinción nuclearcon el método de marcaje in situdel ADN fragmentado, junto a un patrón en bandas en la electroforesis sobre gel de agarosa de ADN aislado [19,20]. Estos datos se han interpretado comoindicativos de apoptosis [21]. Sin embargo, la morfología de las células muertas después de un episodiode isquemia global transitoria no es la típica de apoptosis y, por tanto, puede argumentarse que la muerte celular retardada secundaria a isquemia global transitoria difiere de las clásicas necrosis o apoptosis [22].

Finalmente, la hipoxia-isquemia en el cerebro en desarrollo produce un gran número de células muertas con morfología apoptótica, que se tiñen con el método de marcaje in situdel ADN fragmentado, hecho que se asocia con un patrón típico en bandas en la electroforesis sobre gel de agarosa de ADN aislado [22-24].

Frente a estos datos, debe señalarse que se puede producir fragmentación internucleosomal y al azar del ADN en las células necróticas. Como resultado, las células necróticas pueden teñirse con el método de marcaje in situ del ADN fragmentado [25,26]. Laconfirmación de muerte apoptóticarequiere la combinación de cambios morfológicos y bioquímicos característicos.

\section{FACTOR DE TRANSCRIPCIÓN C-JUN Y C-JUN N-TERMINAL CINASA-1 (JNK-1)}

Los factores de transcripción de las familias fos y jun son los componentes principales de la activación de las secuencias AP-1 en el ADN, y participan en diversas funciones celulares, entre ellas la proliferación celular, la transcripción génica, las respuestas de estrés, de regeneración o de muerte [27-32]. El resultado tan diverso de laactuación de estos factores de transcripción se explica por las distintas posibilidades de formación de dímeros entre los diferentes miembros de las familias o de uniones con otros factores de transcripción, así como por cambios en la fosforilación del factor de transcripción. Por ejemplo, la desfosforilación de thr-231, ser-243 y ser-249 dec-jun aumenta la actividad de unión a AP-1, mientras que la fosforilación de ser-63 y serina 73 (ser-73) delmismoc-junaumentaelpotencial postranscripcionaldec-jun. ElJNK-1 se une y fosforila c-jun en los lugares activos de serina y activalatranscripción $[33,34]$. Estudiosrecientes hanmostrado la estrechaimplicación de c-jun y de JNK-1 como mediadores de supervivencia, regeneración o muerte neuronal [35].
Sehademostradounainducción de ARNmensajero(ARNm) de c-jun en la corteza cerebral y caudado/putamen después de isquemia focal por oclusión unilateral de la arteria cerebral media en la rata [36,37]. Estainducción se continúa con la expresión de la proteína c-jun en las zonas periféricas de la lesión, pero no en la zona central del área infartada, lo que indica un bloqueo de la síntesis de esta proteína en las neuronas con muerte temprana [38-42]. Ello parece indicar que la expresión de c-jun es una respuesta al estrés isquémico, pero que la proteína no es necesaria para que se produzca muerte celular por necrosis en las zonas centrales del infarto. Sin embargo, estudios más recientes han mostrado fosforilación en la ser-73 de parte del c-jun, asociado a activación de JNK-1, después de isquemia focal [43]. El aspecto más importante es que las células que expresan c-jun fosforilado en la ser-73 presentan daño nuclear, como se demuestra por la colocalización de c-jun fosforilado y ADN fragmentado mediante inmunohistoquímica y marcaje in situ del ADN fragmentado [43]. De este modo, si bien el aumento de la expresión de c-jun es una respuesta no específica frente al estrés isquémico, la fosforilación de c-jun en la ser-73 está asociada a muerte celular por apoptosis en las células localizadas alrededor de la zona central del infarto.

Laisquemiaglobal transitoria poroclusión bilateral de carótidas produce una inducción de ARNm de c-jun en todas las regiones del hipocampo, incluyendo CA1,CA3 y circunvolución dentada. Laexpresión de proteína c-jun solamente se produce en CA3 y circunvolución dentada, es decir, en las zonas que sobreviven el episodio isquémico [44-46]. Sin embargo, c-jun se expresa en CA1 durante y después de la adquisición de un estado tolerante a la isquemia, lo que sugiere una asociación de c-jun con la supervivenciacelular[47].Lasituación es probablemente máscompleja, ya que la expresión de c-jun en el modelo de isquemia global transitoria en el jerbo se acompaña de cambios moleculares en proteínas reconocidas con alguno de los anticuerpos dirigidos contra c-jun y se asocia a un aumento de la expresión de JNK-1 [48].El estudio con anticuerpos que reconozcan c-jun fosforilado en ser-73 sería enormemente útil para conocer su posible expresión en las células de CA1 en este modelo de muerte celular retardada de isquemia global.

En la rata en desarrollo (octavo día posnatal) sometida a hipoxia-isquemia, se ha demostrado una inducción de ARNm para c-jun, especialmente en el lado de la ligadura unilateral de carótida, pero también discretamente en el hemisferio contralateral [49-51].Laexpresióndec-jun/AP-1(N), anticuerpodirigidofrente a los aminoácidos 95 a 105 de c-jun, se limita a las células apoptóticas en estemodelodehipoxia-isquemia [51,52].Unaconclusión semejante puede obtenerse en un modelo de hipoxia-isquemia en la rata joven (21-25 día posnatal), en el que se ha observado una expresión aumentada de c-jun en neuronas que sufrirán muerte retardada, pero no en las neuronas que mueren por necrosis [53]. Al igual que en el adulto, la presencia de c-jun no parece ser factor suficiente, ya que éste se expresa también en el lado contralateral a la isquemia [54]. No se conocen, por el momento, estudios acerca de la fosforilación de c-jun y la posible activación de JNK-1 en el modelo de hipoxia-isquemia cerebral duranteeldesarrollo.

\section{FAMILIA BCL-2}

Los genes de la familia bcl-2 codifican proteínas que regulan la muertecelular programadaen diferentes condiciones fisiológicas 
y patológicas [55,56]. Bcl-2 promueve la supervivencia celular [57,58], mientras que bax acelera la muerte apoptótica [59]. Elgen bcl-x codifica dos proteínas: bcl-xL, que inhibe la muerte celular, y bcl-xS, que inhibe la supervivencia celular [60-62]. La formación de dímeros entre los distintos miembros de la familia bcl-2 tiene un papel fundamental en el destino de las células en diversos paradigmas de apoptosis y supervivencia celular [63] .

La sobrexpresión de bcl-2 en ratones transgénicos protege a las neuronas frente a la isquemia inducida por oclusión permanente de la arteria cerebral media; en los ratones transgénicos el volumen de infarto se reduce en un $50 \%$ comparado con los controles [64]. Deun modo semejante, la sobrexpresión debcl-2humanoa través de un vector de virus herpes reduce el daño isquémico debido a isquemia focal $[65,66]$. Sin embargo, las respuestas de los miembros de la familia bcl-2 no parecen tan sencillas en animales con dotación fisiológica de bcl-2.

Estudiosiniciales mostraron una reducción de la expresión de bcl-2, bcl-x y bax en el caudado/putamen, junto a reducción de bcl-2 y de bcl-x, pero un aumento de bax en la corteza y en el tálamo ipsilateral después de la oclusión de la arteria cerebral media en la rata [67]. En la misma línea de resultados, se ha descrito que estas modificaciones se producen tras la pérdida de inmunorreactividad paraproteínaasociadaamicrotúbulode tipo 2 (MAP-2), utilizada como marcador de proteínas del citoesqueleto, en la zona de infarto, pero preceden a la pérdida de inmunorreactividad para MAP-2 en las zonas periféricas alárea de infarto en un modelo de isquemia focal en el ratón [68]. Otros estudios han corroborado una reducción de bcl-2 en la zona de infarto, pero han mostrado un aumento de bcl-2 en las regiones que rodean al infarto[69,70]. De un modo más detallado, se han distinguidodos zonas en el borde del infarto: en la zona interna se observa un aumentodelaexpresión debcl-x y debax, mientras queenlazona externa se observauna expresión aumentada de bcl-x y bcl-2 [70]. Estudios con doble marcaje para miembros de la familia bcl-2 y marcaje in situ de ADN fragmentado han mostrado que las neuronas que sobrexpresan bax en la zona interna de la penumbra presentan fragmentación del ADN, mientrasquelas neuronasque sobrexpresan bcl-2 en la zona externa no muestran daño nuclear [70]. Tomados conjuntamente, estos datos parecen indicarque, si bien los miembros de la familia de bcl-2 no desempeñan un papel relevante en la zona del infarto, la sobrexpresión de bax se asocia con muerte, mientras que la sobrexpresión de bcl-2 se asocia con supervivencia neuronal en las zonas de penumbra en el infarto cerebral producido porisquemia focal.

Los estudios en isquemia global transitoriahan ofrecidoresultados divergentes. Se ha descrito inducción de ARNm de bcl-2 y bcl-x, sin modificaciones de ARNm de bax, en la región CA1 del hipocampo del jerbo, vulnerable al daño isquémico, después de isquemiaglobal transitoria [71], asícomoun aumento de lainmunorreactividad parabcl-2 en CA1 acompañandola adquisición de tolerancia producida por un breve períodode isquemia en el mismo modelo experimental [72]. Sin embargo, otros estudios han mostrado una ausencia de inducción de bcl-2, pero un incremento en la expresión de bax, en la región CA1 delhipocampo del jerbo $[73,74]$ y de la rata [75] después de isquemia global transitoria.El papel protector de bcl-2 parece apoyarse indirectamente con la observación del aumento de su expresión en las neuronas deCA3, una región resistente a la isquemia, en un modelo de isquemia global en la rata [75]. Por otra parte, el papel favorecedor de muerte de bax se apoya en la observación de su expresión aumentada en otros modelos de isquemia [76]. Nuestros estudios de isquemia global transitoria en el jerbo [77] han mostrado expresión de bcl-2, bax y bcl-x en las neuronas de CA1, indicando así que la presencia de bcl-2 noes suficiente para prevenir la muerte celular en animales con dotaciones fisiológicas de bcl-2. Las interacciones de bcl- 2 con otros miembros de la familia, así como otros factores parecen tener un papel más relevante que la mera presenciao ausencia de expresión de bcl-2.Un aspectodiferencial importante parece ser la expresión aumentada de bcl-xS coincidiendocon la muerte de neuronas en CA1 en modelos de isquemia global en la rata [78] y en el jerbo [79].

Por lo que respecta a la expresión de miembros de la familia bcl-2 en hipoxia/isquemia durante el desarrollo, se ha descrito un aumento de expresión de bax en las neuronas hipocámpicas en ratas de tres semanas sometidas a oclusión unilateral permanente decarótiday 15 minutos dehipoxia [79].Estudios más detallados han mostrado una reducción de bcl-2, bax y bcl-x en las células necróticas, peroexpresión de éstos en el $60 \%$ de las neuronas con morfología apoptótica en un modelo de hipoxia/isquemia en ratas de ocho días [80]. Estudios con inmunoblots han mostrado una discreta reducción global de bcl-2 a las 24 horas y un aumento discreto de bcl-xS a las 12 horas en el mismo modelo de hipoxia/ isquemia en la rata en desarrollo [80]. Si bien estos datos indican un papel poco definido de los miembros de la familia bcl-2 en la supervivencia o muerte celular secundaria a hipoxia/isquemia durante el desarrollo en animales con una dotación fisiológica de estas proteínas, parece ser que bcl-x puede desempañar un papel en la muerte celular. En esta misma línea se ha descrito que la sobrexpresión de bcl-xL es neuroprotectora frente a la isquemia en la rata en desarrollo [81].

\section{CASPASAS}

La familia de las caspasas incluye, por el momento, trece cisteinoproteasas con capacidad de partir residuos de ácido aspártico (c-aspasas), y que se subdividen en tres subfamilias. La familia de proteasas semejantes a enzimas conversoras de interleucina-1 $\beta$ (ICE, del inglés, Interleukin-1ßConverting Enzyme) incluye las caspasas 1 (ICE), 4 (ICE-rel-II), 5 (ICE-rel-III), 11, 12 y 13. La subfamilia ced-3 incluye las caspasas 3 (CPP32), 6 (Mch2), 7 (Mch3), 8(Mch5, FLICE), 9(Mch6, ICE-LAP6) y 10 (Mch4). La tercera subfamilia se compone de un solo miembro, la caspasa 2(Nedd2). Las caspasas actúan sobre un gran número de sustratos, entre ellas las proteínas del citoesqueleto y estructurales, proteínas relacionadas con el ciclo celular, con la escisión y reparación del ADN, con la transcripción y traducción de señales, con transducción de señales y proteinocinasas, precursores de citocinas y con otras proteínas dispares como miembros de la familia bcl-2, huntingtina, atrofina-1, ataxina-3, proteína de la atrofia dentato-rubro-pálido-luisiana y presenilinas. Las caspasas intervienen en la respuesta inflamatoria y en las vías de la muerte celular por apoptosis. La acción de las caspasas puede bloquearse con distintos inhibidores naturales comolos productos del gen CrmA (cytokin responsemodifierenzyme A) del virus de la vacuna, el producto de $35 \mathrm{kDa}(\mathrm{p} 35)$ de baculovirus y diferentes miembros de la familia de genes inhibidores de la apoptosis (IAP). Asimismo, existen inhibidores sintéticos más o menos específicos para las distintas caspasas (Ac-YVAD-CHO, Ac-YVAD-AMC YVAD.CMK, preferentemente inhibidoras de ICE; Ac-DEVD-CHO e z-DEVD.FMK, preferentemente de caspasa 3 y z-VAD.FMK, inhibidor de distintas caspasas). Estosinhibidores, por una parte, posibilitan el estudio de la función 
de las caspasas en distintas formas de muerte celulary, por otra, abren un campo importante en el aspecto terapéutico del control de la muerte celular [82-88].

Laimplicación de las caspasas en la isquemia cerebral es un aspecto emergente, pero todavía poco conocido. Los ratones transgénicos y nulos para ICE presentan una zona menor de infarto y menor edema que los ratones controles frente a la isquemia [89-91], lo que implica que la caspasa 1 interviene en la muerte celular por isquemia. Ello se complementa con la observación de que la inyección de inhibidores de ICEreducen el daño isquémico [92,93], así como conla demostración del aumentode inmunorreactividad para ICE [93] y con la presencia de productos de fragmentación de ICE (p35 y p20, en lugar de p45) en isquemiafocal poroclusión (2 horas) de la arteria cerebral media en ratones y ratas [93]. La actuación de ICE no es clara en la isquemia global transitoria, ya que se ha demostrado un aumento de expresión en células de la microglía, pero no en las neuronas, del hipocampo del jerbo después de la oclusión transitoria de ambas carótidas [94].

Por lo que respecta a la caspasa 3 , se ha comprobado un aumentode productos de ladestrucción de laespectrina(SBDP120) y su inhibición con un inhibidor de caspasas (Z-D-DCB) en células cerebrocorticales cultivadas y sometidas a deprivación de oxígeno y de glucosa [95], así como una inducción de ARNm de caspasa 3 después de la oclusión permanente de la arteria cerebral media en la rata [96]. El estudio más elegante de la actuación de caspasa 3 en la isquemia cerebral se fundamenta en la demostración de expresión de formas degradadas de caspasa 3 (p20 en lugardep32)en células destinadasamorir(reveladasconel método de marcaje in situ del ADN fragmentado) en un modelo de isquemia focal de 2 horas por oclusión de la arteria cerebral media en ratones [97]. La caspasa 3 parece tener también una función relevante en la muerte celular retardada en el hipocampo después de isquemiaglobal transitoria [98].

\section{FACTOR NEUROTRÓFICO DERIVADO DEL CEREBRO EN LA PREVENCIÓN DE LA MUERTE NEURONAL ISQUÉMICA}

ElBNFC es un miembro de la familia de las neurotrofinas que se une con gran afinidad al dominio extracelular del receptor específicotirosincinasa TrkB, produce la fosforilación de su dominio catalíticointracelulary promueve la supervivenciay elcrecimiento de diferentes poblaciones neuronales diana [99-102].

Se ha observado una modificación en la inducción y en la expresión de BDNF y de sus receptores en distintos modelos de isquemia en el cerebro adulto y en el cerebro en desarrollo.

En la rata adulta, la isquemia focal permanente, producida por oclusión unilateral de la arteria cerebral media, da lugar a un aumento en la expresión de ARNm de BDNF y de TrkB en una región amplia alrededor de la zona de infarto, asícomobilateralmente en el hipocampo [103]. Se ha descrito unainducción bilateral semejante de ARNm de BDNF después de isquemia focal en un modelo de isquemia-reperfusión [104].Laisquemia focal transitoria de 15 minutos en el territorio de la arteria cerebral media, que no produce infarto, se acompaña de una inducción de ARNm de BDNFen la corteza ipsilateral y en la corteza cingular alrededor de la zona isquémica, mientras que la isquemia transitoria de 2 horas, que conduce auninfartofocal, se acompaña de unainducción de ARNm de BDNFen la corteza ipsilateral alrededor de la región delinfarto, asícomo, bilateralmente, en las regiones CA1 y CA3 del hipocampo y en la circunvolución dentada [105]. El patrón de inducción de ARNm de BDNFes, por tanto, semejante en laisquemia focal permanente y en laisquemia focal transitoria, cuandoéstaes losuficientementegravecomoparaproducirinfarto focal. En ambos casos, la zona central de isquemia no muestra inducción de BDNF.

La isquemia global transitoria de 2 a 10 minutos en la rata se sigue de una inducción de ARNm de BDNF en la circunvolución dentada a las 2 horas, y de un aumento de la expresión de la proteína BDNFen la circunvolución dentada a las 6horas y en la región CA3 del hipocampo una semana más tarde; mientras que la expresión de BDNF se reduce en la corteza cerebral y en la regiónCA1 delhipocampo[106,107].

Estos datos indican una reducción en la expresión de BDNF en las regiones que pueden sufrir muerte celular por isquemia y un aumento en la expresión de BDNFen las regiones que sobreviven un accidente isquémico. De estos datos puede inferirse que la administración exógena de BDNF puede tener efectos terapéuticosen laregiónisquémica. Dehecho, laadministración de BDNF intraventricularoen infusión sobre la región isquémica reduce el tamaño del infarto secundario a isquemia focal por oclusión de la arteria cerebral media en la rata [108,109]. Lainfusión de BDNF también disminuye el daño celular producido por isquemia global transitoria en larata [110,111].

Los mecanismos que regulan este efecto protector probablemente se producen comoconsecuencia de lainteracción de BDNF con TrkB, su receptor específico. Las neuronas de los ganglios raquídeos dorsales que contienen BDNFcolocalizan TrkB y no requieren soporte trófico adicional en cultivo. El bloqueo de la producción de BDNF mediante la adición de oligonucleótidos contra BDNF en el medio de cultivo se traduce en una reducción en la producción de BDNF y se acompaña de un aumento de muerte neuronal, lo que indica un sistema autocrino BDNF/ TrkB en la supervivencia de subpoblaciones neuronales en el ganglioraquídeo dorsal [112]. Laisquemia global transitoriaen el jerbo da lugar a muerte neuronal en la región CA1 del hipocampo con la excepción de las neuronas que colocalizan BDNF y TrkB, hecho que sugiere también un sistema autocrino BDNF/ TrkB de supervivencia neuronal en este modelo [113]. En esta mismalínea, el injerto en el hipocampodel jerbode fibroblastos transfectados para producir BDNF origina una expresión aumentada de TrkB en las neuronas del hipocampo, y este aumento de expresión tiene un efecto protector frente al daño isquémico por isquemia global transitoria [114]. Estos datos corroboran el efecto protector de BDNF en la isquemia y sugieren que dicho efecto protector se produce a través de la señal de BDNF con su receptor específico.

Esta conclusión se ve refrendada y ampliada en modelos de daño hipóxico-isquémico en el cerebro en desarrollo. El daño hipóxico-isquémico en la rata en desarrollo se acompaña de una inducción de ARNm de BDNFen las regiones no dañadas [115], de un modo parecido a lo que sucede en el adulto. Sin embargo, se observa un marcado aumento en la expresión de TrkB en las neuronas de diferentes regiones cerebrales [116]. Lainfusión de BDNF intraventricular en ratas sometidas a hipoxia-isquemia en el séptimo día posnatal se acompaña de una marcada fosforilación de TrkB y de una reducción del $90 \%$ del daño tisular, si BDNF se empieza a administrar 24 horas antes, o de un $50 \%$ si la administración de BDNF se inicia poco después del insulto hipóxicoisquémico [117]. El efecto protector de BDNFes mucho menoren ratas que sufren un daño hipóxico-isquémico a la edad de 21 días 
y este peor resultado se acompaña de una reducida fosforilación de TrkB [117].

Enresumen, estos datosindicanquelaadministración deBDNF reduce el daño isquémico producido por isquemia focal o por isquemia global transitoria y que los efectos son mejores durante el desarrollo que en el adulto. Asimismo, estos datos señalan el papel clave de la interacción de BDNF con su receptor específico en el sistema de señales que conduce a una mayor supervivencia neuronal frente al insulto isquémico.

\section{CONCLUSIONES}

No está clara todavía la cascada de cambios moleculares que conducen a la muerte celular por isquemia. Por lo que respecta a la posible interacción de miembros de la familia bcl-2, caspasas y factores tróficos, algunos estudios in vitro han permitido obtener datos potencialmente relevantes. El insulto hipóxico en células corticales de rata cultivadas conduce a la muerte porapoptosis que semanifiesta, en primerlugar, poruna reducción en la expresión de bcl-2 y, en segundo lugar, por un aumento de expresión de caspasas 1 y 3 . Inhibidores de las caspasas 1 y 3 protegen a las células delos cambios morfológicos distintivosdeapoptosis, pero no previenen la reducción en la expresión de bcl-2 [118]. La adición de factores tróficos al medio (en particular IGF-1 obFGF) reducen las modificaciones de bcl-2 y de caspasas, y la muerte celular por hipoxia en células corticales en cultivo [118].

\section{BIBLIOGRAFÍA}

1. Kerr JFR, Harmon BV. Definition and incidence of apoptosis: an historical perspective. In Tomei LD, Cope FO, eds. Apoptosis: the molecular basis of cell death. New York: Cold Spring Harbor Laboratory Press; 1991. p. 5-30.

2. Gerschenson LE, Rotello RJ. Apoptosis: a different type of cell death. FASEB J 1992; 6: 2450-5.

3. Buja LM, Eigenbrodt ML, Eigenbrodt EH. Apoptosis and necrosis. Basic types and mechanisms of cell death. Arch Pathol Lab Med 1993; 117: 1208-14.

4. Gavrieli Y, Sherman Y, Ben-Sasson SA. Identification of programmed cell death in situ via labeling of nuclear DNA fragmentation. J Cell Biol 1992; 119: 493-501.

5. Ellis RE, Yuan J, Horvitz HR. Mechanisms and functions of cell death. Annu Rev Cell Biol 1991; 7: 663-98.

6. Driscoll M. Cell death in C. elegans: molecular insights into mechanisms conserved between nematodes and mammals. Brain Pathol 1996; 6: 411-25.

7. Stewart BW. Mechanisms of apoptosis: integration of genetic, biochemical, and cellular indicators. J Natl Cancer Inst 1994; 86: 1286-96.

8. Wyllie AH. The genetic regulation of apoptosis. Curr Opin Genet Dev 1995; 5: 97-104.

9. Steller H. Mechanisms and genes of cellular suicide. Science 1995; 267:1445-9.

10. Kroemer G, Petit P, Zamzami N, Vayssière JL, Mignotte B. The biochemistry of programmed cell death. FASEB J 1995; 9: 1277-87.

11. Raff MC. Social controls on cell survival and cell death. Nature 1992; 356: $397-400$.

12. Silos-Santiago I, Greelund LJS, Johnson EM, Snider WD. Molecular genetics of neuronal survival. Curr Opin Neurobiol 1995; 5: 42-9.

13. Burek MJ, Oppenheim RW. Programmed cell death in the developing nervous system. Brain Pathol 1996; 6: 427-46.

14. Tominaga T, Kure S, Narisawa K, Yoshimoto T. Endonuclease activation following focal ischemic injury in the rat brain. Brain Res 1993; 608:21-6.

15. Linnik MD, Zobrist RH, Hatfield MD. Evidence supporting a role for programmed cell death in focal cerebral ischemia in rats. Stroke 1993; 24:2002-9.

16. MacManus JP, Hill IE, Huang ZG, Rasquinha I, Xue D, Buchan AM. DNA damage consistent with apoptosis in transient focal ischemic neocortex. Neuroreport 1994; 5:493-6.

17. Li Y, Chopp M, Jiang N, Yao F, Zaloga C. Temporal profile of in situ DNA fragmentation after transient middle cerebral artery occlusion in the rat. J Cereb Blood Flow Metab 1995; 15: 389-97.

18. Linnik MD, Miller JA, Sprinkle-Cavallo J, Mason PJ, Thompson FY, Montgomery LR, et al. Apoptotic DNA fragmentation in the rat cerebral cortex induced by permanent middle cerebral artery occlusion. Mol Brain Res 1995; 32: 116-24.

19. MacManus JP, Buchan AM, Hill IE, Rasquinha I, Preston E. Global ischemia can cause DNA fragmentation indicative of apoptosis in rat brain. Neurosci Lett 1993; 164: 89-92.

20. Héron A, Pollard H, Dessi F, Moreau J, Lasbennes F, Ben-Ari Y, et al. Regional variability in DNA fragmentation after global ischemia evidenced by combined histological and gel electrophoresis observations in the rat brain. J Neurochem 1993; 61: 1973-6.

21. Nitatori T, Sato N, Waguri S, Karasawa Y, Araki H, Shibanai K, et al. Delayed neuronal death in the CA1 pyramidal cell layer of the gerbil hippocampus following transient ischemia is apoptosis. J Neurosci 1995; 15: 1001-11.

22. Ferrer I, Tortosa A, Macaya A, Sierra A, Moreno D, Munell F, et al. Evidence of internucleosomal DNA fragmentation following hypoxia- ischemia in the infant rat brain, and transient forebrain ischemia in the adult gerbil. Brain Pathol 1994; 4: 115-22.

23. Hill IE, MacManus JP, Rasquinha I, Tuor UI. DNA fragmentation indicative of apoptosis following unilateral cerebral hypoxia-ischemia in the neonatal rat. Brain Res 1995; 676: 398-403.

24. Beilharz EJ, Williams CE, Dragunow M, Sirimanne ES, Gluckman PD. Mechanisms of delayed cell death following hypoxic-ischemic injury in the immature rat: evidence for apoptosis during selective neuronal loss. Mol Brain Res 1995; 29: 1-14.

25. Charriaut-Marlangue C, Ben-Ari Y. A cautionary note on the use of the TUNEL stain to determine apoptosis. Neuroreport 1995; 7: 61-4.

26. De Torres C, Munell F, Ferrer I, Reventós J, Macaya A. Identification of necrotic cell death by the TUNEL assay in the hypoxic-ischemic neonatal rat brain. Neurosci Lett 1997; 230: 1-4

27. Sheng M, Greenberg ME. The regulation and function of c-fos and other immediate early genes in the nervous system. Neuron 1990;4:477-85.

28. Morgan JI, Curran T. Stimulus-transcription coupling in the nervous system: involvement of the inducible proto-oncogenes fos and jun. Annu Rev Neurosci 1991; 14: 421-51.

29. Herdegen T, Zimmermann M. Expression of c-Jun and Jun D transcription factors represent specific changes in neuronal gene expression following axotomy. Progr Brain Res 1994; 103: 153-71.

30. Gass P, Herdegen T. Neuronal expression of AP-1 proteins in excitotoxic-neurodegenerative disorders and following nerve fiber lesions. Progr Neurobiol 1995; 47: 257-90.

31. Dragunow M, Preston K. The role of inducible transcription factors in apoptotic cell death. Brain Res Rev 1995; 21: 1-28.

32. Ferrer I, Olivé M, Ribera J,Planas AM. Naturally-occurring (programmed) and radiation-induced apoptosis are associated with selective c-Jun expression in the developing rat brain. Eur J Neurosci 1996; 8: 1286-98.

33. Hibi M, Lin A, Smeal T, Minden A, Karin M. Identification of an oncoprotein- and UV-responsive protein kinase that binds and potentiates the c-jun activation domain. Genes Dev 1993; 7: 2135-48.

34. Derijard B, Hibi M, Wu IH, Barrett T, Su B, Deng T, et al. JNK-1: a protein kinase stimulated by UV light and Ha-Ras that binds and phosphorylates the c-Jun activation domain. Cell 1994; 76: 1025-37.

35. Herdegen T, Skene P, Bähr M. The c-Jun protein-transcriptional mediator of neuronal survival, regeneration and death. Trends Neurosci 1997; 20: 227-31.

36. An G, Lin TN, Liu JS, Xue JJ, He YY, Hsu CY. Expression of c-fos and c-jun family genes after focal cerebral ischemia. Ann Neurol 1993; $33: 457-64$.

37. Comelli MC, Guidolin D, Seren MS, Zanoni R, Canella R, Rubini R, et al. Time course, localization and pharmacological modulation of immediate early inducible genes, brain-derived neurotrophic factor and trkB messenger mRNAs in the rat brain following photochemical stroke. Neuroscience 1993; 55: 473-90.

38. Gass P, Spranger M, Herdegen T, Bravo R, Köck P, Hacke W, el al. Induction of FOS and JUN proteins after focal ischemia in the rat: differential effect of the N-methyl-D-aspartate receptor antagonist MK-801. Acta Neuropathol 1992; 84: 545-53.

39. Kiessling M, Gass P. Stimulus-transcription coupling in focal cerebral ischemia. Brain Pathol 1994; 4: 77-83.

40. Planas AM, Ferrer I. Expressió gènica en models d'isquèmia cerebral. Treballs Soc Cat Biol 1996; 47: 227-47.

41. Guégan C, Lévy V, David JP, Ajchenbaum-Cymbalista F, Sola B. c-Jun and cyclin D1 proteins as mediators of neuronal death after focal ischemic insult. Neuroreport 1997; 8: 1003-7.

42. Hermann DM, Kuroiwa T, Ito U, Mies G. Expression of c-jun, hsp-72 and GFAP following repeated unilateral common carotid artery occlu- 
sion in gerbils-correlates of delayed ischemic injury. Brain Res 1998; 799: 35-43.

43. Herdegen T, Claret FX, Kallunki T, Martín-Villalba A, Winter C, Hunter T, et al. Lasting N-terminal phosphorylation of c-Jun and activation of c-Jun N-terminal kinases after neuronal injury. J Neurosci 1998; 18: 5124-35.

44. Nowak TS, Osborne OC, Suga S. Stress protein and proto-oncogene expression as indicators of neuronal pathophysiology after ischemia. Progr Brain Res 1993; 96: 195-208.

45. Kiessling M, Stumm G, Xie Y, Herdegen T, Aguzzi A, Bravo R, et al. Differential transcription and translation of immediate early genes in the gerbil hippocampus after transient global ischemia. J Cereb Blood Flow Metab 1993; 13: 914-24.

46. Takemoto $\mathrm{O}$, Tominoto $\mathrm{H}$, Yanagihara $\mathrm{T}$. Induction of $\mathrm{c}$-fos and c-jun gene products and heat shock protein after brief and prolonged cerebral ischemia in gerbils. Stroke 1995; 26: 1639-48.

47. Sommer C, Gass P, Kiessling M. Selective c-Jun expression in CA1 neurons of the gerbil hippocampus during and after acquisition of an ischemic tolerant state. Brain Pathol 1995; 5: 135-44.

48. Ferrer I, Ballabriga J, Pozas E. Transient forebrain ischemia in the adult gerbil is associated with a complex c-Jun response. Neuroreport 1997; 8: 2483-7.

49. Gubits RM, Burke RE, Casey-Macintosh G, Bendele A, Munell F. Immediate early gene induction after neonatal hypoxia-ischemia. Mol Brain Res 1993; 18: 228-38.

50. Munell F, Burke RE, Bandele A, Gubits RM. Colocalization of c-fos, c-jun and hsp-70 mRNA expression in brain after neonatal hypoxia-ischemia. Dev Brain Res 1994; 77: 111-21.

51. Macaya A, Munell F, Ferrer I, de Torres C, Reventós J. Cell death and associated c-jun induction in perinatal hypoxia-ischemia. Effects of the neuroprotective drug dexamethasone. Mol Brain Res 1998; 56 29-37.

52. Ferrer I. Cell death in the normal developing brain, and following ionizing radiation, methyl-azoxymethanol acetate, and hypoxia-ischaemia in the rat. Neuropathol Appl Neurobiol 1996; 22: 489-94.

53. Dragunow M, Beilharz E, Sirimanne E, Lawlor P, Williams C, Bravo $\mathrm{R}$, et al. Immediate-early gene protein expression in neurons undergoing delayed cell death, but not necrosis, following hypoxic-ischemic injury to the young rat brain. Mol Brain Res 1994; 25: 19-33.

54. Gilby KL, Armstrong JN, Currie RW, Robertson HA. The effects of hypoxia-ischemia on expression of c-Fos, c-Jun and HSP-70 in the young rat hippocampus. Mol Brain Res 1997; 48: 87-96.

55. Davies JC. The Bcl-2 family of proteins, and the regulation of cell survival. Trends Neurosci 1995;18:355-8.

56. Merry DE, Korsmeyer SJ. Bcl-2 gene family in the nervous system. Annu Rev Neurosci 1997; 20: 245-67.

57. Hockenberry D, Núñez G, Milliman CL, Scheriber RD, Korsmeyer $\mathrm{SJ}$. Bcl-2 is an inner mitochondrial membrane protein that blocks programmed cell death. Nature 1990; 348: 334-6.

58. Korsmeyer SJ. Bcl-2: a repressor of lymphocyte death. Immunol Today 1992;13: 285-8.

59. Oltvai ZN, Milliman CL, Korsmeyer SJ. Bcl-2 heterodimerizes in vivo with a conserved homolog, Bax, that accelerates programmed cell death. Cell 1993; 74: 609-19.

60. Boise LH, González-García M, Postema CE, Ding L, Lindsten T, Tur$\mathrm{ka} \mathrm{LA}$, et al. Bcl-x, a bcl-2-related gene that functions as a dominant regulator of apoptosic cell death. Cell 1993; 74: 597-608

61. González-García M, Pérez-Ballesteros R, Ding L, Duan L, Boise LH, Thompson CB, et al. Bcl-xL is the major bcl-x mRNA form expressed during murine development and its product localizes in mitochondria. Development 1994;120: 3033-42.

62. Minn AJ, Boise LH, Thompson CB. Bcl-x(S) antagonizes the protective effects of Bcl-x(L). J Biol Chem 1996; 271: 6306-12.

63. Oltvai ZN, Korsmeyer SJ. Checkpoints of dueling dimers foil death wishes. Cell 1994; 74: 609-19.

64. Martinou JC, Dubois-Dauphin M, Staple JK, Rodríguez I, Frakowski $\mathrm{H}$, Missotten $\mathrm{M}$, et al. Overexpression of $\mathrm{Bcl}-2$ in transgenic mice protects neurons from naturally occurring cell death and experimental ischemia. Neuron 1994; 13: 1017-30.

65. Linnik MD, Zahos P, Geschwind MD, Fedoroff HJ. Expression of bcl-2 from a defective herpes simplex virus-1 vector limits neuronal death in focal cerebral ischemia. Stroke 1995; 26: 1670-4.

66. Lawrence MS, Ho DY, Sun GH, Steinberg GK, Sapolsky RM. Overexpression of bcl-2 with herpes simplex virus vectors protects CNS neurons against neurological insults in vitro and in vivo. J Neurosci 1996; 16: 486-96.

67. Guillardon F, Lenz C, Waschke KF, Krajewski S, Reed JC, Zimmermann $\mathrm{M}$, et al. Altered expression of Bcl-2, Bcl-x, Bax, and c-Fos co-localizes with DNA fragmentation and ischemic damage following middle cerebral artery occlusion in rats. Mol Brain Res 1996; 40: 254-60.

68. Matsushita K, Matsuyama T, Kitagawa K, Matsumoto M, Yanagihara T, Sugita M. Alterations of Bcl-2 family proteins precede cytoskeletal proteolysis in the penumbra, but not in infarct cortex following focal cerebral ischemia in mice. Neuroscience 1998; 83: 439-48.

69. Chen J, Graham SH, Chan PH, Lan J, Zhou RL, Simon RP. Bcl-2 is expressed in neurons that survive focal ischemia in the rat. Neuroreport $1995 ; 6: 394-8$.

70. Isenmann S, Stoll G, Schroeter M, Krajewski S, Reed JC, Bahra M. Differential regulation of Bax, Bcl-2, and Bcl-x proteins in focal cortical ischemia in the rat. Brain Pathol 1998; 8: 49-62.

71. Honkaniemi J, Massa S, Breckinridge M, Sharp FR. Global ischemia induces apoptosis-associated genes in hippocampus. Mol Brain Res 1996; 42: 79-88.

72. Shimazaki K, Ishida A, Kawai N. Increase in Bcl-2 oncoprotein and the tolerance to ischemia-induced neuronal death in the gerbil hippocampus. Neurosci Res 1994; 20: 95-9.

73. Hara A, Iwai T, Niwa M, Uematsu T, Yoshimi N, Tanaka T, et al. Immunohistochemical detection of $\mathrm{Bax}$ and $\mathrm{Bcl}-2$ proteins in gerbil hippocampus following transient forebrain ischemia. Brain Res 1996; 711: 249-53.

74. Niwa M, Hara A, Iwai T, Sassa T, Mori H, Uematsu T. Expression of $\mathrm{Bax}$ and $\mathrm{Bcl}-2$ protein in the gerbil hippocampus following transient forebrain ischemia and its modifications by phecycline. Neurol Res 1997; 19: 629-33.

75. Chen J, Zhu RL, Nakayama M, Kawaguchi K, Jin K, Stetler RA, et al Expression of the apoptosis effector gene bax is up-regulated in vulnerable hippocampal neurons following global ischemia. J Neurochem 1996; 67: 64-71.

76. Krajewski S, Mai JK, Krajewska M, Sikorska A, Mossakowski MJ, Reed JC. Upregulation of Bax protein levels in neurons following cerebral ischemia. J Neurosci 1995; 15: 6364-76.

77. Ferrer I, López E, Blanco R, Rivera R, Ballabriga J, Pozas E, et al. $\mathrm{Bcl}-2$, Bax, and $\mathrm{Bcl}-\mathrm{x}$ expression in the $\mathrm{CA} 1$ area of the hippocampus following transient forebrain ischemia in the adult gerbil. Exp Brain Res 1998;121: 167-73.

78. Dixon ED, Stephenson DT, Clemens JA, Little SP. Bcl-x-S is elevated following severe global ischemia in rat brain. Brain Res 1997; 776: 222-9.

79. MacGibbon GA, Lawlor PA, Sirimanne ES, Walton MR, Connor B, Young $\mathrm{D}$, et al. Bax expression in mammalian neurons undergoing apoptosis, and in Alzheimer's disease hippocampus. Brain Res 1997; 750: 223-34.

80. Ferrer I, Pozas E, López E, Ballabriga J. Bcl-2, Bax and Bcl-x expression following hypoxia-ischemia in the infant rat brain. Acta Neuropathol 1997; 94: 583-9.

81. Parsadanian AS, Cheng Y, Keller-Peck CR, Holtzman DM, Snider WD. $\mathrm{Bcl}-\mathrm{xL}$ is an antiapoptotic regulator for postnatal CNS neurons. J Neurosci 1998; 18: 1009-19.

82. Kumar S, Lavin MF. The ICE family of cysteine proteases as effectors of cell death. Cell Death Differ 1996; 3: 255-67.

83. Cohen GM. Caspases: the executioners of apoptosis. Biochem J 1997; 326: 1-16.

84. Nicholson DW, Thornberry NA. Caspases: killer proteases. Trends Biochem 1997; 22: 299-306.

85. Van de Craen M, Vandenabeele P, Declerq W, van den Brande I, van Loo G, Kolemans F, et al. Characterization of seven murine caspase family members. FEBS Lett 1997; 403: 61-9.

86. Friedlander RM, Yuan J. ICE, neuronal apoptosis and neurodegeneration. Cell Death Differ 1998; 5: 823-31

87. Stroh C, Schulze-Osthoff K. Death by thousand cuts: an even increasing list of caspase substrates. Cell Death Differ 1998; 5: 997-1000.

88. Schulze-Osthoff K, Ferrari D, Los M, Wesselborg S, Peter ME. Apoptosis signaling by death receptors. Eur J Biochem 1998; 254: 439-59.

89. Friedlander RM, Gagliardini V, Hara H, Fink KB, Li W, MacDonald $\mathrm{G}$, et al. Expression of a dominant negative mutant of ICE in transgenic mice prevents neuronal cell death induced by trophic factors withdrawal and ischemic brain injury. J Exp Med 1997; 185: 933-40.

90. Hara H, Fink K, Endres M, Friedlander RM, Gagliardini V, Yuan J, et al. Attenuation of transient focal cerebral ischemic injury in transgenic mice expressing a mutant ICE inhibitor protein. J Cereb Blood Flow Metab 1997; 17: 370-5.

91. Schielke GP, Yang GY, Shivers BD, Betz AL. Reduced ischemic brain injury in interleukin-1 $\beta$ converting enzyme-deficient mice. J Cereb Blood Flow Metab 1998; 18: 180-5.

92. Loddick SA, MacKenzie A, Rothwell NJ. An ICE inhibitor, z-VAD-DCB attenuates ischemic brain damage in the rat. Neuroreport 1996; 7: 1465-8.

93. Hara H, Friedlander RM, Gagliardini V, Ayata C, Fink K, Huang Z, et al. Inhibition of interleukin $1 \beta$ converting enzyme family proteases reduces ischemic and excitotoxic neuronal damage. Proc Natl Acad Sci USA 1997; 94: 2007-12. 
94. Bhat RV, DiRocco R, Marcy VR, Flood DG, Zhu Y, Dobrzanski P, et al. Increased expression of IL-1 $\beta$ converting enzyme in hippocampus after ischemia: selective localization in microglia. J Neurosci 1996; 16: 4146-54

95. Nath R, Probert A, McGinnis KK, Wang KK. Evidence of activation of caspase-3-like protease in excitotoxin- and hypoxic/hypoglycemic-injured neurons. J Neurochem 1998; 71: 186-95.

96. Asaki M, Hoshimaru M, Uemura Y, Tokime T, Kojima M, Ohtsuka $\mathrm{T}$, et al. Expression of interleukin- $1 \beta$ converting enzyme gene family and bcl-2 gene family in the rat brain following permanent occlusion of the middle cerebral artery. J Cereb Blood Flow Metab 1997; 17: 11-8.

97. Nawamura S, Zhu J, Fink K, Endres M, Srinivasan A, Tomaselli KJ, et al. Activation and cleavage of caspase- 3 in apoptosis induced by experimental cerebral ischemia. J Neurosci 1998; 18: 3659-68.

98. Chen J, Nagayama T, Jin K. Induction of caspase-3-like protease may mediate delayed neuronal death in the hippocampus after transient cerebral ischemia. J Neurosci 1998; 18: 4914-28.

99. Barde YA. Neurotrophins: a family of proteins supporting the survival of neurons. Progr Clin Biol Res 1994; 390: 45-56.

100. Barbacid M. Neurotrophic factors and their receptors. Curr Opin Cell Biol 1995; 7: 148-55.

101. Bothwell M. Functional interactions of neurotrophins and neurotrophin receptors. Annu Rev Neurosci 1995; 18: 223-53.

102. Lewin GR, Barde YA. Physiology of neurotrophins. Annu Rev Neurosci 1996; 19: 289-317.

103. Arai S, Kinouchi H, Akabane A, Owada Y, Kamii H, Kawase M, et al. Induction of brain-derived neurotrophic factor (BDNF) and the receptor TrkB mRNA following middle cerebral artery occlusion in rat. Neurosci Lett 1996; 211: 57-60.

104. Lin TN, Chen JJ, Wang SJ, Cheng JT, Chi SI, Shyu AB, et al. Expression of NGFI-B mRNA in a rat focal ischemia-reperfusion model. Mol Brain Res 1996; 43: 149-56.

105. Kokaia Z, Zhao Q, Kokaia M, Elmer E, Metsis M, Smith ML, et al. Regulation of brain-derived neurotrophic factor gene expression after transient middle cerebral occlusion with and without brain damage. Exp Neurol 1995; 136: 73-88.

106. Lindwall O, Ernfors P, Bengzon J, Kokaia Z, Smith ML, Siesjo BK, et al. Differential regulation of mRNAs for nerve growth factor, brain-derived neurotrophic factor, and neurotrophin-3 in the adult rat

\section{MECANISMOS DE MUERTE NEURONAL}

\section{EN LA ISQUEMIA CEREBRAL}

Resumen. Introducción. Estudios morfológicos y bioquímicos han mostrado un componente apoptótico en la muerte neuronal producida por isquemia focal y por isquemia global en el adulto y por hipoxia-isquemia en el desarrollo. Desarrollo. En la cascada que conduce a la muerte celular participan distintos factores, entre ellos factores de transcripción, miembros de la familia Bcl-2, caspasas y factores tróficos. El factor de transcripción c-jun es inducido y expresado en los tres modelos de isquemia como respuesta no específica al estrés isquémico. El papel de los miembros de la familia Bcl-2 no es claro en los distintos modelos de isquemia. Es posible que la expresión de Bcl-2 no sea suficiente para proteger a las neuronas de la muerte en animales con dotación fisiológica de esta proteína. También, que Bcl-xS puede desempeñar un papel en la muerte neuronal por isquemia global en el adulto y por hipoxia-isquemia durante el desarrollo. Estudios recientes han mostrado la participación de caspasa 1 y de caspasa 3 en isquemia focal y en isquemia global en el adulto. Finalmente, el insulto isquémico se acompaña de cambios en la expresión de neurotrofinas y de sus receptores. Conclusiones. La administración de factor neurotrófico derivado del cerebro (BDNF) protege a las células de la muerte en los modelos de isquemia focal y global en el adulto y de hipoxia-isquemia durante el desarrollo. Este efecto probablemente está relacionado con el sistema de señales entre BDNF y su receptor específico TrkB. Existen suficientes resultados experimentales en los distintos modelos de isquemia como para argumentar la administración de BDNF como agente terapéutico en patología isquémica humana [REV NEUROL 1999; 29: 515-21].

Palabras clave. Apoptosis. Bax. Bcl-2. Bcl-x. Caspasa. C-jun. $C$-jun $N$-terminal cinasa-1. Factor neurotrófico derivado del cerebro. Necrosis. TrkB. brain following cerebral ischemia and hypoglycemic coma. Proc Natl Acad Sci USA 1992; 89: 698-52.

107. Kokaia Z, Nawa H, Uchino H, Elmer E, Kokaia M, et al. Regional brain-derived neurotrophic factor mRNA and protein levels following transient forebrain ischemia in the rat. Mol Brain Res 1996; 38: 139-44.

108. Schäbitz WK, Schwab S, Spranger M, Hacke W. Intraventricular brain-derived neurotrophic factor reduces infarct size after focal cerebral ischemia in rats. J Cereb Blood Flow Metab 1997; 17: 500-6.

109. Yamashita K, Wiessner C, Lindholm D, Thoenen H, Hossmann KA. Post-occlusion treatment with BDNF reduces infarct size in a model of permanent occlusion of the middle cerebral artery in rat. Metab Brain Dis 1997; 12: 271-80.

110. Tsukahara T, Yonekawa Y, Tanaka K, Ohara O, Watanabe S, Kimura $\mathrm{T}$, et al. The role of brain-derived neurotrophic factor in transient forebrain ischemia in the rat brain. Neurosurgery 1996; 34: 323-31.

111. Beck T, Lindholm D, Castrén E, Wree A. Brain-derived neurotrophic factor protects against ischemic cell damage in rat hippocampus. J Cereb Blood Flow Metab 1994; 14: 689-92.

112. Acheson A, Conover JC, Fandl JP, DeChiara TM, Russell M, Thadani $\mathrm{M}$, et al. A BDNF autocrine loop in adult sensory neurons prevents cell death. Nature 1995; 374: 450-3.

113. Ferrer I, Ballabriga J, Martí E, Pozas E, Planas AM, Blasi J. BDNF and TrkB co-localize in CA1 neurons resistant to transient forebrain ischemia in the adult gerbil. J Neuropathol Exp Neurol 1997; 56: 790-7.

114. Ferrer I, Ballabriga J, Martí E, Pérez E, Alberch J, Arenas E. BDNF up-regulates TrkB protein and prevents the death of CA1 neurons following transient forebrain ischemia. Brain Pathol 1998; 8: 253-61.

115. Dragunow M, Beilharz E, Sirimanne E, Lawlor P, Williams C, Branco $\mathrm{R}$, et al. Immediate-early gene protein expression in neurons undergoing delayed death, but not necrosis, following hypoxic-ischaemic injury to the young rat brain. Mol Brain Res 1994; 25: 19-33.

116. Narumiya S, Ohno M, Tanaka N, Yamano T, Shimada M. Enhanced expression of full-length TrkB receptors in young rat brain with hypoxic-ischemic injury. Brain Res 1998; 797: 278-86.

117. Cheng Y, Gidday JM, Yan Q, Shah AR, Holtzman DM. Marked age-dependent neuroprotection by brain-derived neurotrophic factor against neonatal hypoxic-ischemic brain injury. Ann Neurol 1997; 41: 521-9.

118. Tamatani M, Ogawa S, Tohyama M. Roles of Bcl-2 and caspases in hypoxia-induced neuronal death: a possible neuroprotective mechanism of peptide growth factors. Mol Brain Res 1998; 58: 27-39.

\section{MECANISMOS DE MORTE NEURONAL NA ISQUÉMIA CEREBRAL}

Resumo. Introdução. Os estudos morfológicos e bioquímicos demonstraram uma componente apoptótica de morte neuronal, produzida no adulto, pela isquémia focal e por isquémia generalizada e pela hipóxico-isquémia no desenvolvimento. Desenvolvimento. No circuito que conduz à morte cerebral, participam diferentes factores, entre os quais factores de transcrição, membros da família Bcl-2, caspases e factores tróficos. O factor de transcrição c-Jun, é induzido e é expresso nas três formas de isquémia, como resposta não específica ao stress isquémico. A função dos membros da família Bcl-s, não está muito clara nas diferentes formas de apresentação da isquémia. É possível que só a expressão do Bcl-2, não seja suficiente para proteger os neurónios da morte, nos animais que têm fisiologicamente esta proteína. Por outro lado, o Bcl-xS pode desempenhar um papel na morte neuronal por isquémia generalizada no adulto e por hipóxico-isquémia durante o desenvolvimento. Estudos recentes demonstraram a participação da caspase 1 e da caspase 3 na isquémia focal e na isquémia generalizada do adulto. Finalmente, a agressão isquémica vê-se acompanhada por alterações na expressão de neurotrofinas e dos seus receptores. Conclusões. A administração de factor neurotrófico derivado do cérebro (BDNF), protege as células da morte nas formas de isquémia focal e generalizada do adulto e de hipóxico-isquémia durante o desenvolvimento. Este efeito está provavelmente relacionado com os sistemas de sinais entre o BDNF e o seu receptor específico TrkB. Existe um número suficiente de resultados experimentais, nas diferentes apresentações de isquémia, para defender administração de BDNF como agente terapêutico na patologia isquémica humana [REV NEUROL 1999; 29: 515-21].

Palavras chave. Apoptose. Bax. Bcl-x. Caspase. C-jun. C-jun N-terminal kinase-1. Factor neurotrófico derivado do cérebro. Necrose. $\operatorname{TrkB}$. 